\title{
The Applying Of The Romanowski Test For Identification Of Data Affected By Errors
}

\author{
Ioan Milosan, PhD, Prof. \\ Transilvania University of Brasov, Romania
}

doi: 10.19044/esj.2016.v12n21p18 URL:http://dx.doi.org/10.19044/esj.2016.v12n21p18

\begin{abstract}
The paper presents an example of calculation to identify data affected by aberrant errors and removing these data from the values of elongation (A) and impact strength (KC) of $\mathrm{Ni}-\mathrm{Cu}$ austempered ductile iron, by applying the Romanowski tests. All accepted values as fair were noted with the Yes and all values affected by errors were noted with No. This test has identified two aberrant errors of the experimental data. In this way, the experimental results obtained are validated with a statistical confidence level of 95\%.
\end{abstract}

Keywords: ADI, data affected by aberrant errors, Romanowski test

\section{Introduction}

In Materials Science, the statistical methods are very important in an understanding and interpreted the results of a scientific researched work.

In a lot of experimental data it can happen that some abnormal values to be higher or lower than the rest of the results so it is very important to identify data affected by aberrant errors. Errors is defined by Webster (Bevington et al., 2003) as "the different between an observed or calculated value and the true value" so if we can eliminate the errors of our researched work, with accurate data we can interpret the correct evolution of the processes

The measured value of our experimental data, are never exactly representative of the studied processes, because of a numerous factors involved in the studied process and because of the tools and of the measurement mode (Peters, 2001). Mathematically this was materialized in the relationship:

measured value $=$ true value \pm error

The question which arises is to use statistical tests to identify abnormalities and removing these data because of incorrect information about the study that they can induce. 


\section{Research objectives}

This research have an important objective, to made an calculation for identification of data affected by aberrant errors by applying the Romanowski test. for the results of elongation (A) and impact strength (KC) of $\mathrm{Ni}-\mathrm{Cu}$ austempered ductile iron.

\section{Steps for applying the Romanowski test}

Identifying data affected by aberrant errors can be accomplished by applying the Romanowski tests.

Solving the test is done in the following steps (Costescu, 2008; Tanasescu, 1987):

(1) Grouping of data and determining the minimum $\left(\mathrm{x}_{\min }\right)$ and maximum $\left(\mathrm{x}_{\max }\right)$ of the experimental values;

(2) Calculating the arithmetic average, with the relationships:

$$
\bar{x}=\frac{1}{n-1}\left(x_{1}+x_{2}+. .+x_{n}\right)=\frac{1}{n-1} \sum_{i=1}^{n-1} x_{i}
$$

where:

$\mathrm{n}=$ the number of experimental determinations;

$\bar{x}=$ the arithmetic average of the experimental data. For Romanowski test, the average value $\bar{x}$ is calculated without considering the value $x_{0}$ which is analysed;

$\mathrm{x}_{0}=$ the liable data to be affected by aberrant errors for the Romanowski test;

(3) Calculating the dispersion, with the relationships:

$\mathrm{s}^{2}=\frac{1}{n-1}\left[\left(x_{1}-\bar{x}\right)^{2}+. .+\left(x_{n}-\bar{x}\right)^{2}=\frac{1}{n-1} \sum_{i=1}^{n-1}\left(x_{i}-\bar{x}\right)^{2}\right.$

where: $s^{2}=$ the dispersion of the experimental data;

$\mathrm{s}=\sqrt{s^{2}}$

(4) Calculating the average square diverting, with the relationships:

where: $\mathrm{s}=$ the average square diverting of the experimental data;

(5) Calculating the Romanowski test, with the relationships:

$t_{\text {calc }}=\frac{\left|x_{0}-\bar{x}\right|}{s \sqrt{n /(n-1)}}$

where: $t$ calculated value

(6) Determining the critical value of test the Romanowki test, with the relationships:

$t_{c r i t}=t_{\alpha ; v}$

where: 
$t_{\text {crit }}=$ the critical value for the $t$ test is the tabular value on the basis of the number of values in the series of data and confidence interval;

$\alpha=$ the coefficient of statistical confidence level, $\alpha=0.05$ (Bulgaru et al., 2001). In this way, the experimental results obtained are validated with a statistical confidence level of 95\%. For a 95\% probability, level 1- $\alpha=0.95$ and $\alpha=0.05$. Conventionally used probability levels are the $90 \%$ (somewhat confident), 95\% (fairly confident), and 99\% (quite confident) probability levels (Peters, 2001);

$v=$ the number of degrees of freedom, $v=n-1$ for the Romanowski test;

(7) Comparing the $t$ calculated value with the critical value $t_{\text {crit }}$ and analyzing the results and the conclusions of this test; two situations can occur (Banica, 2015):

a) If $t<t_{c r i t}$ the values of the liable data to be affected by aberrant errors $\left(\mathrm{x}_{0}\right)$ of the experimental values are normal for our experimental research;

b) If $t>t_{\text {crit }}$ the values of liable data to be affected by aberrant errors $\left(\mathrm{x}_{0}\right)$ of the experimental values; In both cases when determining abnormal after removing them, the calculations will made using new parameters required analysis.

\section{Materials}

Over the last few years, a number of thermal processes have been developed to modify the matrix structure and thus the properties of ductile cast iron (Harding, 2007).

Austempered Ductile Iron (A.D.I.) with a bainitic matrix, obtained by heat treatment and isothermal hardening is the material which combines a lot of superior attributes of the classical Austempered Ductile Irons or forged iron, being in a serious competition with the iron used by the moment in the automotive industry (Rimmer, 2004).

Depending on heat treatment parameters, in these material components owing to changes in proportions of the major phases present in the microstructure: bainitic ferrite, high carbon austenite and graphite nodules. Martensite, ferrite, iron carbides and other alloy carbides may also be present (Chou et al., 1992).

Because the final structure obtained, influence property values, a wide range of properties can be obtained in these special material.

The studied cast iron had the following composition: $3.63 \% \mathrm{C} ; 2.88$ \%Si; 0.45 \%Mn; $0.012 \%$; $0.006 \%$ S; $0.48 \% \mathrm{Ni} ; 0.42 \% \mathrm{Cu} ; 0.050 \% \mathrm{Mg}$.

This cast iron was elaborated in an induction furnace. Nodular changes were obtained with the "In mold" method, with the help of prealloy FeSiCuMg with $10-16 \% \mathrm{Mg}$, added into the reaction chamber in a proportion of $1.1 \%$ of the treated cast iron. 
The structure in raw state is perlito-feritic typical for a cast iron with geometrically regular nodular form. The casted raw iron had the following mechanical properties: $\mathrm{Rm}=652 \mathrm{~N} / \mathrm{mm}^{2}, \mathrm{HB}=176, \mathrm{KC}=11 \mathrm{~J} / \mathrm{cm}^{2}, \mathrm{~A}=13$ $\%$.

\section{Heat treatments}

The parameters of the heat treatment done were the following: for the lots $\mathrm{A}, \mathrm{B}$ and $\mathrm{C}$, submitted to isothermal hardening, the austenizing temperature $\mathrm{T}_{\mathrm{A}}=900\left[{ }^{\circ} \mathrm{C}\right]$, the maintained time at austenizing temperature, $\tau$ $\mathrm{A}=60[\mathrm{~min}]$ for all the lots.

The temperature at isothermal level, for all the lots was: $\mathrm{T}_{\mathrm{iz}}=350$ $\left[{ }^{\circ} \mathrm{C}\right]$ for lot $\mathrm{A}, 375\left[{ }^{\circ} \mathrm{C}\right]$ for lot $\mathrm{B}$ and $400\left[{ }^{\circ} \mathrm{C}\right]$ for lot $\mathrm{C}$; the maintained time at the isothermal level, $t_{\mathrm{iz}}=60$ [min]. All these 3 experimental lots were performed at isothermal maintenance in salt-bath, being the cooling after the isothermal maintenance was done in air.

\section{Experimental results}

The experiment groups performed at isothermal maintenance in saltbath (55\% $\left.\mathrm{KNO}_{3}+45 \% \mathrm{NaNO}_{3}\right)$, being the cooling after the isothermal maintenance was done in air. From this material, 30 specific elongation (A) and impact strength (KC) specimens and was done. For the impact strength the specimens was notched. For each $\mathrm{KC}$ and A determination it was done 10 parallel determination $(\mathrm{r}=10)$. The values of the mechanical results are presented in table 1 and 2.

Table 1. Data Analysis of elongation (A) values for $\mathrm{T}_{\mathrm{A}} 900^{\circ} \mathrm{C}$

\begin{tabular}{|l|l|l|l|}
\hline $\begin{array}{l}\text { Parallel } \\
\text { observations }\end{array}$ & \multicolumn{3}{|l|}{ Samples, $\mathrm{k}=30$} \\
\hline $\mathrm{r}=10$ & $\begin{array}{l}\mathrm{T}_{\mathrm{iz}}=350^{\circ} \mathrm{C} \\
(\mathrm{lot} \mathrm{A})\end{array}$ & $\begin{array}{l}\mathrm{T}_{\mathrm{iz}}=375^{\circ} \mathrm{C}(\text { lot } \\
\mathrm{B})\end{array}$ & $\begin{array}{l}\mathrm{T}_{\mathrm{iz}}=400^{\circ} \mathrm{C} \\
(\text { lot } \mathrm{C})\end{array}$ \\
\hline Obs 1 & 5.8 & 6.6 & 8.0 \\
\hline Obs 2 & 5.7 & 7.3 & 7.9 \\
\hline Obs 3 & 6.0 & 6.9 & 7.7 \\
\hline Obs 4 & 6.3 & 6.6 & 8.0 \\
\hline Obs 5 & 5.4 & 6.3 & 7.5 \\
\hline Obs 6 & 5.8 & 7.2 & 7.6 \\
\hline Obs 7 & 5.5 & 7.4 & 7.9 \\
\hline Obs 8 & 6.5 & 7.5 & 7.9 \\
\hline Obs 9 & 5.6 & 7.3 & 6.8 \\
\hline Obs 10 & 5.5 & 6.4 & 7.1 \\
\hline
\end{tabular}


Table 2. Data Analysis of impact strength (KC) values for $\mathrm{T}_{\mathrm{A}} 900^{\circ} \mathrm{C}$

\begin{tabular}{|l|l|l|l|}
\hline $\begin{array}{l}\text { Parallel } \\
\text { observations }\end{array}$ & \multicolumn{3}{|l|}{ Samples, $\mathrm{k}=30$} \\
\hline $\mathrm{r}=10$ & $\begin{array}{l}\mathrm{T}_{\mathrm{iz}}=350^{\circ} \mathrm{C} \\
\text { (lot A) }\end{array}$ & $\begin{array}{l}\mathrm{T}_{\mathrm{iz}}=375^{\circ} \mathrm{C} \\
\text { (lot B) }\end{array}$ & $\begin{array}{l}\mathrm{T}_{\mathrm{iz}}=400^{\circ} \mathrm{C} \\
\text { (lot C) }\end{array}$ \\
\hline Obs 1 & 72 & 82 & 99 \\
\hline Obs 2 & 71 & 91 & 98 \\
\hline Obs 3 & 75 & 86 & 96 \\
\hline Obs 4 & 78 & 82 & 99 \\
\hline Obs 5 & 67 & 78 & 93 \\
\hline Obs 6 & 72 & 90 & 94 \\
\hline Obs 7 & 68 & 92 & 98 \\
\hline Obs 8 & 81 & 93 & 98 \\
\hline Obs 9 & 70 & 91 & 84 \\
\hline Obs 10 & 68 & 79 & 88 \\
\hline
\end{tabular}

It can be certainly observed a normal evolution of the values for mechanical characteristics (Batra et al., 2003):

- with increasing temperature from 350 to 400 degrees is observed that increased the values of the studied mechanical properties.

This evolution of the mechanical properties is determined by the structural changes reported to the parameters of the heat treating. This evolution of the mechanical properties is determining by the structural constituents for each heat treatment.

In the case of lot A, structure can be constituted of inferior bainite, superior bainite and residual austenite.

In the case of lot $\mathrm{C}$, structure can be constituted of superior bainite, residual austenite and the inferior bainite will disappear. These constituents are determining high values for $\mathrm{A}$ and $\mathrm{KC}$ for lot $\mathrm{C}$ compared with lot $\mathrm{A}$.

The values of the Romanowski test for the data sets are presented in tables 3 and 4.

Table 3. Romanowski test for elongation (A) data sets

\begin{tabular}{|c|c|c|c|c|c|c|c|}
\hline Lot & $\mathrm{x}$ & $\begin{array}{l}\text { Measured } \\
\text { values }\end{array}$ & - & $\mathrm{s}$ & $\mathrm{t}_{\text {calc }}$ & $\mathrm{t}_{\text {crit }}$ & $\begin{array}{l}\text { Values } \\
\text { remains } \\
\text { Yes/No }\end{array}$ \\
\hline \multirow{2}{*}{$\begin{array}{l}\mathrm{A} \\
\left(\mathrm{T}_{\mathrm{iz}}=350^{\circ} \mathrm{C}\right)\end{array}$} & $\mathrm{X}_{\max }$ & 6.5 & 5.733 & 0.071 & 0.266 & \multirow{6}{*}{2.35} & YES \\
\hline & $\mathrm{X}_{\min }$ & 5.4 & 5.855 & 0.109 & 0.330 & & YES \\
\hline \multirow{2}{*}{$\begin{array}{l}\mathrm{B} \\
\left(\mathrm{T}_{\mathrm{iz}}=375^{\circ} \mathrm{C}\right)\end{array}$} & $\mathrm{X}_{\max }$ & 7.5 & 6.888 & 0.161 & 0.401 & & YES \\
\hline & $\mathrm{X}_{\min }$ & 6.3 & 7.022 & 0.146 & 0.382 & & YES \\
\hline \multirow{2}{*}{$\begin{array}{l}\mathrm{C} \\
\left(\mathrm{T}_{\mathrm{iz}}=400^{\circ} \mathrm{C}\right)\end{array}$} & $\mathrm{X}_{\max }$ & 8.0 & 7.600 & 0.149 & 0.386 & & YES \\
\hline & $\mathrm{X}_{\min }$ & 6.8 & 7.733 & 0.078 & 0.279 & & YES \\
\hline
\end{tabular}

Comparing the $t$ calculated value, $\mathrm{t}_{\text {calc }}$ with the critical value $t_{c r i t}$ and analyzing the results for the Romanowski test, two situations can occur:

a) If $t_{\text {calc }}<t_{c r i t}$ the values of the minimum ( $\left.x_{\min }\right)$ and maximum ( 
$\mathrm{X}_{\max }$ ) of the experimental values are normal for our experimental research, in this case it noted with a Yes;

b) If $t_{\text {calc }}>t_{\text {crit }}$ the values of the minimum $\left(\mathrm{x}_{\min }\right)$ and maximum ( $\mathrm{x}_{\max }$ ) of the experimental values are identified as data affected by aberrant errors for our experimental research, in this case it noted with a No;

Table 4. Romanowski test for impact strength (KC) data sets

\begin{tabular}{|c|c|c|c|c|c|c|c|}
\hline Lot & $\mathrm{x}$ & $\begin{array}{l}\text { Measured } \\
\text { values }\end{array}$ & $\bar{x}$ & $\mathrm{~S}$ & $\mathrm{t}_{\text {calc }}$ & $\mathrm{t}_{\text {crit }}$ & $\begin{array}{l}\text { Values } \\
\text { remains } \\
\text { Yes/No }\end{array}$ \\
\hline \multirow{2}{*}{$\begin{array}{l}\mathrm{A} \\
\left(\mathrm{T}_{\mathrm{iz}}=350^{\circ} \mathrm{C}\right)\end{array}$} & $\mathrm{X}_{\max }$ & 81 & 71.222 & 3.359 & 2.927 & \multirow{6}{*}{2.35} & $\mathrm{NO}$ \\
\hline & $\mathrm{X}_{\min }$ & 67 & 72.778 & 4.184 & 1.311 & & YES \\
\hline \multirow{2}{*}{$\begin{array}{l}\mathrm{B} \\
\left(\mathrm{T}_{\mathrm{iz}}=375^{\circ} \mathrm{C}\right)\end{array}$} & $\mathrm{X}_{\max }$ & 93 & 85.667 & 5.228 & 1.807 & & YES \\
\hline & $\mathrm{X}_{\min }$ & 78 & 87.333 & 4.899 & 1.332 & & YES \\
\hline \multirow{2}{*}{$\begin{array}{l}\mathrm{C} \\
\left(\mathrm{T}_{\mathrm{iz}}=400^{\circ} \mathrm{C}\right)\end{array}$} & $\mathrm{X}_{\max }$ & 99 & 94.222 & 4.871 & 3.273 & & $\mathrm{NO}$ \\
\hline & $\mathrm{x}_{\min }$ & 84 & 95.889 & 3.446 & 0.930 & & YES \\
\hline
\end{tabular}

By studying all the data presented in table 3 and 4, following a general remarkable conclusions:

(a) all values are accepted as correct data (Yes) with exception the following values noted with No, which have been identified as data affected by aberrant errors :

- the value of $x_{\max }=81$, from the impact strength $(\mathrm{KC})$ data of lot $\mathrm{A}$, $\mathrm{t}_{\text {calc }}=2.927, \mathrm{r}_{\text {crit }}=2.35$ so $t_{\text {calc }}>t_{\text {crit }}$;

- the value of $x_{\max }=99$, from the impact strength (KC) data of lot $\mathrm{C}$, $\mathrm{t}_{\text {calc }}=3.273, \mathrm{r}_{\text {crit }}=2.35$ so $t_{\text {calc }}>t_{\text {crit }}$;

For this two experiments it was eliminated the value affected by aberrant errors and recovery the test without these values, until they finally obtain a value that confirms initial relationship: $t_{\text {calc }}<t_{\text {crit }}$. These new experimental value is normal for our experimental research and in this case it noted with a Yes for the column of the table representing values remains.

\section{Conclusion:}

Analyzing all data taken into account, there can say the following:

(a) The evolution of the mechanical properties is determined by the structural changes reported to the parameters of the heat treating and this evolution of the mechanical properties is determining by the structural constituents for each heat treatment;

(b) In the case of lot A, structure can be constituted of inferior bainite, superior bainite and residual austenite.

(c) In the case of lot $\mathrm{C}$, structure can be constituted of superior bainite, residual austenite and the inferior bainite will disappear. These constituents are determining high values for $\mathrm{A}$ and $\mathrm{KC}$ for lot $\mathrm{C}$ compared with lot A (e) In the case of lots A, structure can be constituted of inferior 
bainite, residual austenite and martensite .These constituents are determining high values for $\mathrm{R}_{\mathrm{m}}$ and $\mathrm{HB}$, and less high for $\mathrm{A}$ and $\mathrm{KCU}$;

(d) By studying all the data presented in the table 3 and 4, following a general remarkable conclusions: all experimental data as correct were noted with Yes and all experimental data as aberrant errors resulting from application, were noted with No;

(e) The $t$ test has identified two aberrant errors. For this two experiments it was eliminated the value affected by aberrant errors and recovery the test without these values, until they finally obtain a value that confirms initial relationship: $t_{\text {calc }}<t_{\text {crit }}$.

\section{References:}

Bevington, P., \& Robinson, K. (2003). Data reduction and error analysis for the physical science, McGraw-Hill Higher Education, New York, USA.

Peters, C. A (2001). Statistics for Analysis of Experimental Data. In Environmental Engineering Processes Laboratory Manual, S. E. Powers, Ed. AEESP (pp. 1-25), Champaign, Illinois, USA.

Costescu, M. R. (2008). Identifying Data Affected by Aberrant Errors. Applied Program, Economic Informatics, 12 (1), pp. 52 - 55.

Tanasescu, I. (1987). Statistical control of processes and products, Bucharest, EDP.

Bulgaru M. \& Bolboaca, L. (2001). Quality engineering. Quality management, statistics and control measurements in 3D, Cluj-Napoca, Alma Mater.

Banica M. \& N. Medan, N. (2015). Statistical analysis of the experimental data obtained in studying of water jet cleaning, Academic Journal of Manufacturing Engineering, 13 (1), pp. 6-10.

Harding, R.A. (2007). The production, properties and automotive applications of austempered ductile iron. KovoveMaterialy, 45, p.1-16.

Rimmer, A. (2004). ADI solutions aid vehicle design. The Foundry Trade Journal, 2, pp. 54-56.

Chou, J. M, Hon, M. H. \& Lee, J. L.(1992). The austenite transformation in ferritic ductile cast iron, Materials Science and Engineering A, 158 (2), pp. 241-249.

Batra, U., Ray, S. \& Prabhakar, S. R. (2003). Effect of austenitization on austempering of copper alloyed ductile iron, Journal of Material Engineering and Performance, 12 (5), pp. 597-601. 